\title{
Pituitary-Adrenal Functions in a Hereditary Hypothyroid (rdw) Rat
}

\author{
Atsushi TOHEI ${ }^{1)}$, Motoaki UMEZU²), Takao KANAI ${ }^{3)}$, Keiichiro YAMAGUCHI ${ }^{4)}$, \\ Akinori $\mathrm{KOSAKU}^{4)}$, Hiroe $\mathrm{KON}^{1)}$, and Motoo SHINODA ${ }^{1)}$ \\ ${ }^{1)}$ Laboratory Animal Research Center, Dokkyo Medical University, 880 Kitakobayashi, Mibu, Tochigi \\ 321-0293, Japan, ${ }^{2}$ Laboratory of Animal Endocrinology and Reproduction, Faculty of Agriculture, \\ Utsunomiya University, 350 Minemachi, Utsunomiya, Tochigi 321-8505, Japan, ${ }^{3)}$ Institute of \\ Laboratory Animals, Tokyo Women's Medical University, 8-1 Kawada-cho, Shinjuku, Tokyo \\ 162-8666, Japan, and ${ }^{4)}$ Department of Pathology, Dokkyo Medical University Hospital, \\ 880 Kitakobayashi, Mibu, Tochigi 321-0293, Japan
}

\begin{abstract}
The rdw rat is a hereditary hypothyroid strain isolated from Wistar-Imamichi rats. In the present study, adrenocorticotropic hormone (ACTH) and corticosterone responses to restraint stress $(120 \mathrm{~min}$ ) were examined in rdw adult male rats. ACTH response to restraint stress was higher in rdw rats than in hetero control rats. The plasma concentrations of corticosterone were lower in rdw rats than in control rats during the first $30 \mathrm{~min}$ after the onset of stress. Both ACTH and corticosterone responses to restraint stress in rdw rats recovered to control levels after thyroxine (T4) replacement therapy. These results suggest that hereditary hypothyroidism causes adrenal dysfunction directly and that hypersecretion of ACTH is a result of reduced corticosterone in rdw rats.
\end{abstract}

Key words: ACTH, corticosterone, hypothyroid

Thyroid hormone has been reported to play an important role in adrenal function [16]. Hypothyroidism reduces the weight of the adrenals [5, 12] and the plasma concentration of corticosterone, and also affects circadian adrenocortical rhythm [8]. We have reported that hypothyroidism causes adrenal dysfunction directly and results in hypersecretion of ACTH [12-14, 16] mediated by corticotropin-releasing hormone $(\mathrm{CRH})$ and arginine vasopressin (AVP) in the hypothalamus [13].

The WIC-Tg ${ }^{r d w}(\mathrm{rdw})$ rat is a hereditary hypothyroid strain which was isolated as a dwarf model from a closed colony of Wistar-Imamichi (WIC) rats [7, 18, 19]. Previous reports have mainly examined reproductive func- tions [2-4] and the abnormalities of the thyroglobulin gene $[1,9,10]$. There has been no study investigating the pituitary-adrenal functions in the rdw rat, although hypothyroidism is known to cause adrenal dysfunction. To investigate the effect of hereditary hypothyroidism on the pituitary-adrenal function, we examined the plasma concentrations of ACTH and corticosterone in response to restraint stress for $2 \mathrm{~h}$ in the present study.

The rdw rats and normal littermates (Wistar-Imamichi) were produced by mating adult $\mathrm{F}_{1}$ male and female rats, as previously reported [2-4]. Adult (12-15 weeks old) male rdw and age-matched hetero control (+/-) rats were used in the present study. The thyroid and adrenal func-

(Received 15 June 2009 / Accepted 4 August 2009)

Address corresponding: A. Tohei, Laboratory Animal Research Center, Dokkyo Medical University, 880 Kitakobayashi, Mibu, Tochigi 321-0293, Japan 
tions in hetero rats were examined in a preliminary study, and it was confirmed that both functions in hetero were normal. Rats were housed under controlled temperature and lighting (lights on from 07:00 to 19:00) conditions and supplied with food and water ad libitum. Five to six animals were used in each experiment. Forty-eight hours before each experiment, a silastic cannula was inserted into the right atrium via the external jugular vein in each rat under ketamine $(75 \mathrm{mg} / \mathrm{kg}$, i.p.) and xylazine $(10 \mathrm{mg} /$ $\mathrm{kg}$, i.p.) anesthesia. Thyroxine (1.5 mg L-Thyroxine, T4: Sigma Chemical Co., St. Louis, MO, USA) was dissolved in $1 \mathrm{ml} 0.1-\mathrm{N} \mathrm{NaOH}$ solution and diluted by water to a final volume of 11 . To avoid repeated needle stimulus of injection of T4, drinking water was chosen as the route of $\mathrm{T} 4$ treatment. The $\mathrm{T} 4$ replacement therapy $(1.5 \mathrm{mg} / \mathrm{l}$ in drinking water) was performed for rdw rats for 4 weeks. The dose and duration of T4 replacement therapy were selected from the observations of a preliminary experiment and the previous reports [3,19]. All procedures were approved by the animal care and use committee of Dokkyo Medical University. To investigate the basal levels of ACTH and corticosterone in rdw rats, animals were sacrificed by decapitation. Trunk blood was collected and centrifuged for the determination of plasma levels of ACTH and corticosterone. After decapitation, the adrenal glands were removed and the adrenal tissues were examined by light- and electron-microscopy. To investigate the pituitary-adrenal function in response to stress, animals were immobilized by a small disposable restrainer (DecapiCone, Braintree Scientific Inc., MA, USA) for 120 min [12, 15]. Blood $(0.3 \mathrm{ml})$ was withdrawn through the atrial cannula at $0,15,30,60$, and 120 min after the onset of restraint stress and replaced with an equal volume of heparinized saline. ACTH $[15,17]$ and corticosterone $[6,15]$ were measured by double-antibody RIAs using ${ }^{125}$ I-labeled radioligands as described previously. Antisera to $\mathrm{ACTH}$ and corticosterone were obtained from IgG Co. (Nashville, TN, USA) and Scantibodies Laboratory Inc. (Santee, CA, USA), respectively. The intra- and inter-assay coefficients of variation were 6.3 and 11.9 for ACTH and 6.8 and 9.5 for corticosterone, respectively. All results are expressed as the mean \pm SEM. The data of the basal hormone levels were analyzed using one-way analysis of variance (ANOVA) followed by
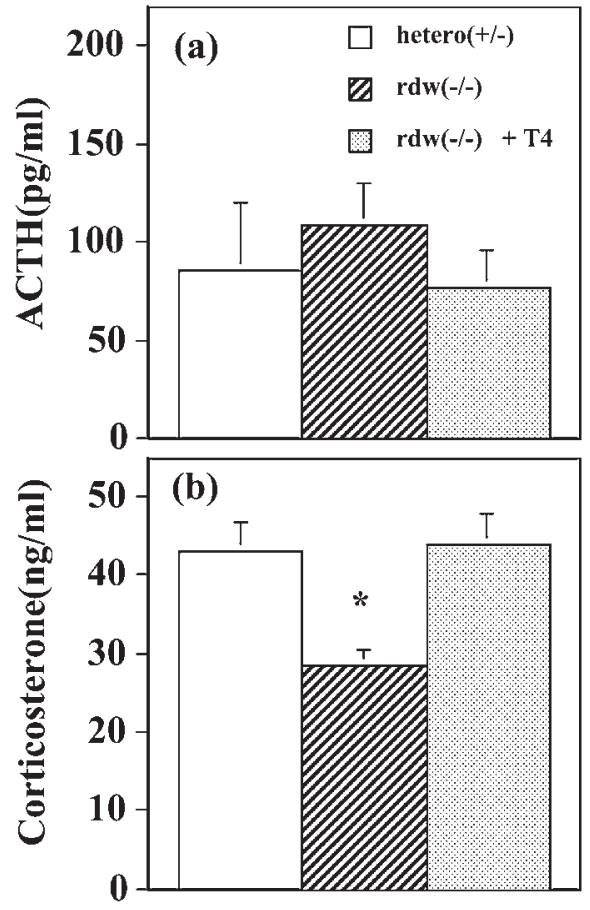

Fig. 1. Plasma concentrations of ACTH (a) and corticosterone (b) in hetero rats $(+/-)$, $\operatorname{rdw}(-/-)$, and $\mathrm{rdw}(-/-)$ treated with $\mathrm{T} 4(1.5 \mathrm{mg} / \mathrm{l}$ in drinking water for 4 weeks). Each point represents the mean \pm SEM of five to six animals. Asterisks indicate $P<0.05$ compared to the value for the hetero control (one-way ANOVA followed by Fisher's PLSD test).

Fisher's protected least significant difference (PLSD) test. The data of the plasma concentrations of ACTH and corticosterone in response to stress were analyzed using two-way ANOVA followed by Fisher's PLSD test; a value of $P<0.05$ was considered significant.

The basal levels of plasma ACTH were not significantly different among the three groups of rats (Fig. 1a; control, rdw and rdw+T4), but the levels of plasma corticosterone showed low values in rdw rats compared to hetero control $(+/-)$ rats and rdw rats treated with $\mathrm{T} 4$ (Fig. 1b). ACTH response to restraint stress was higher in rdw rats than in hetero control rats (Fig. 2a), and the area under the curve (AUC) of ACTH response for rdw rats also showed a higher value than the value for control rats (rdw: $782.73 \pm 62.23 \mathrm{pg} / \mathrm{ml} \times 120 \mathrm{~min}$, hetero; $222.37 \pm 114.97 \mathrm{pg} / \mathrm{ml} \times 120 \mathrm{~min}, \mathrm{~F}=18.45, P<0.01)$. The plasma concentrations of corticosterone were lower in rdw rats than in hetero control rats during the first 30 


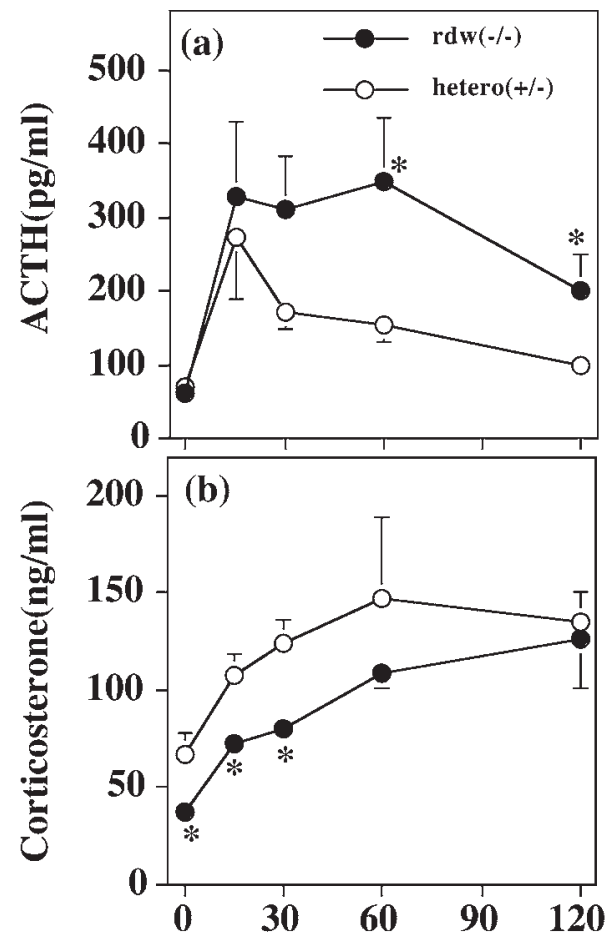

Time after the onset of stress (min)

Fig. 2. Effects of restraint stress on ACTH (a) and corticosterone (b) secretion in hetero (+/-) and $\mathrm{rdw}(-/-)$ rats. Each rat was stressed by immobilization in a small disposable restrainer for $120 \mathrm{~min}$. Each point represents the mean \pm SEM of five animals. Asterisks indicate $P<0.05$ compared to the value for the respective control (two-way ANOVA followed by Fisher's PLSD test).
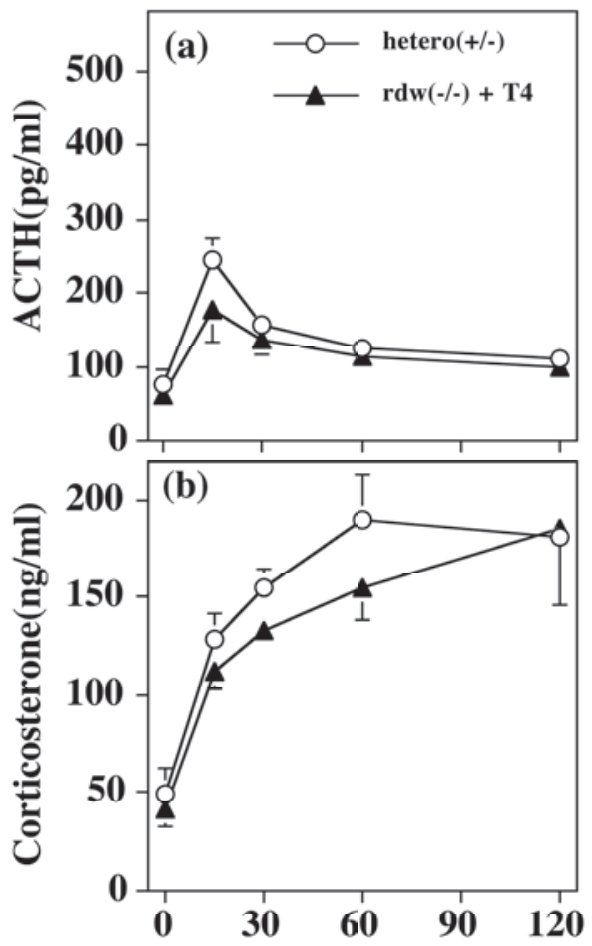

\section{Time after the onset of stress (min)}

Fig. 3. Effects of restraint stress on ACTH (a) and corticosterone (b) secretion in hetero $(+/-)$ and $\mathrm{rdw}(-/-)$ rats treated with T4 $(1.5 \mathrm{mg} / \mathrm{l}$ in drinking water for 4 weeks). Each rat was stressed by immobilization in a small disposable restrainer for $120 \mathrm{~min}$. Each point represents the mean \pm SEM of five animals. Asterisks indicate $P<0.05$ compared to the value for the respective control (two-way ANOVA followed by Fisher's PLSD test). min after the onset of stress, but the value of corticosterone in rdw rats returned to levels similar to those in hetero rats at $120 \mathrm{~min}$ after the onset of stress (Fig. 2b). There was no significant difference in the AUC of the corticosterone response between $\mathrm{rdw}$ and hetero rats $(\mathrm{rdw} ; 250.45 \pm 70.56 \mathrm{ng} / \mathrm{ml} \times 120 \mathrm{~min}$, hetero; 236.05 $\pm 70.56 \mathrm{ng} / \mathrm{ml} \times 120 \mathrm{~min}, \mathrm{~F}=0.038, P>0.05)$. Both $\mathrm{ACTH}$ and corticosterone responses to restraint stress in rdw rats were recovered to control levels after $\mathrm{T} 4$ replacement therapy (Figs. 3a and 3b). Light- and electron-microscope examinations revealed the adrenal was not morphologically different between rdw and hetero control rats.

It is well established that hypothyroidism causes ad- renal dysfunction, and we have previously reported that adrenal dysfunction in hypothyroid rats is induced by thiouracil $[12-14,16]$ treatment and thyroidectomy [14]. In the present study, the basal level of corticosterone in rdw rats was low, and the adrenal dysfunction was confirmed in the hereditary hypothyroid rdw strain. The two models of hypothyroidism (thiouracil-induced and rdw rats) are similar in term of hypothyroidism, but thyroid hormones maintain low levels even in the developmental stages in rdw rats. On the other hand, ACTH secretion was higher in rdw rats than in control rats and this observation also supports our previous observations [12-14, 16]. The plasma concentration of corticosterone at 120 min after the onset of restraint stress in rdw rats had 
returned to a level similar to that in control rats, suggesting that the adrenals can respond to hypersecretion of $\mathrm{ACTH}$, and that corticosterone secretion is maintained in rdw rats under restraint conditions. To clarify the adrenal response in rdw rats in detail, an ACTH challenge test (the response to the same amount of ACTH administration) will be necessary in a future study. In contrast to our results, a previous report by Shi et al. (1994) showed that hypothyroidism causes a reduction in CRH gene transcripts in paraventricular nucleus (hypothalamus) of male rats, with a concomitant decrease in both pro-opiomelanocortin (POMC) gene expression in the anterior pituitary gland and circulating corticosterone, though the plasma levels of POMC related peptides were not reported [11]. We did not examine CRH gene transcription in rdw rats in the present study, but hypersecretion of ACTH in response to restraint stress was observed in rdw rats, suggesting that hypothyroidism causes adrenal dysfunction directly and reduces the negative feedback effects of corticosterone, resulting in hypersecretion of ACTH in rdw rats. The thyroid hormone may affect $\mathrm{CRH}$ gene transcription directly, but the primary action site of it is probably the adrenal gland because rdw rats showed hypersecretion of ACTH.

In summary, adrenal dysfunction was confirmed in the hereditary hypothyroid rdw rats in addition to the thiouracil-induced model in the present study. The present results suggest that hereditary hypothyroidism also causes adrenal dysfunction directly and that hypersecretion of ACTH is a result of reduction of corticosterone.

\section{References}

1. Hishinuma, A., Furudate, S., Oh-ishi, M., Nagakubo, N., Namatame, T., and Ieiri, T. 2000. Endocrinology 141: 4050-4055.

2. Jiang, J.Y., Umezu, M., and Sato, E. 2000. J. Reprod. Fertil. 119: 193-199.

3. Jiang, J.Y., Umezu, M., and Sato, E. 2000 . Biol.Reprod. 63: 1637-1641.

4. Jiang, J.Y., Miyabayashi, K., Nottola, S.A., Umezu, M., Cecconi, S., Sato, E., and Macchiarelli, G. 2008. Histol. Histopathol. 23: 1387-1398.

5. Kamilaris, T.C., DeBold, C.R., Johnson, E.O., Mamalaki, E., Listwak, S.J., Calogero, A.E., Kalogeras, K.T., Gold, P.W., and Orth, D.N. 1991. Endocrinology 128: 25672576.

6. Kanesaka, T., Taya, K., and Sasamoto, S. 1992. J. Reprod. Dev. 38: 85-89.

7. Koto, M., Sato, T., Okamoto, M., and Adachi, J. 1988. Jikken Dobutsu 37: 21-30.

8. Murakami, N., Hayafuji, C., and Takahashi, K. 1984. Acta Endocrinol. 107: 519-524.

9. Oh-ishi, M., Omori, A., Kwon, J.Y., Agui, T., Maeda, T., and Furudate, S.I. 1998. Endocrinology 139: 1288-1299.

10. Rivolta, C.M. and Targovnik, H.M. 2006. Clin. Chim. Acta 374: 8-24.

11. Shi,Z.X., Levy, A., and Lightman, S.L. 1994. Endocrinology 134: $1577-1580$

12. Tohei, A., Akai, M., Tomabechi, T., Mamada, M., and Taya, K. 1997. J. Endocrinol. 152: 147-154.

13. Tohei, A., Watanabe, G., and Taya, K. 1998. J. Endocrinol. 156: $395-400$.

14. Tohei, A., Watanabe, G., and Taya, K. 1998. J. Vet. Med. Sci. 60: 281-285.

15. Tohei, A., Mogi, Y., Kon, H., Hokao, R., and Shinoda, M. 2003. Exp. Anim. 52: 437-439.

16. Tohei, A. 2004. J. Reprod. Dev. 50: 9-20.

17. Tomabechi, T., Taya, K., Akai, M., and Sasamoto, S. 1994. J. Reprod. Dev. 40: 99-104.

18. Umezu, M., Fujimura, T., Sugawara, S., and Kagabu, S. 1993. Jikken Dobutsu 42: 211-216.

19. Umezu, M., Kagabu, S., Jiang, J., and Sato, E. 1998. Lab. Anim. Sci. 48: 496-501. 